\section{THE EFFECTS OF NORMOTHERMIC AND HYPOTHERMIC CARDIOPULMONARY BYPASS ON DEFIBRILLATION ENERGY REQUIREMENTS AND TRANSMYOCARDIAL IMPEDANCE}

Implications for
implantable cardioverter-
defibrillator implantation

The influence of normothermic and hypothermic cardiopulmonary bypass on defibrillation energy requirements and transcardiac impedance is not well characterized. However, this relationship is of clinical importance during automatic defibrillator implantation done with concomitant cardiac surgery, and there is anecdotal information that criteria for successful implantation are harder to achieve after such operations. We studied the effect of controlled hypothermia on defibrillation energy requirements and transcardiac impedance in a canine model of cardiopulmonary bypass in which 26 animals underwent right atrial and femoral arterial cannulation, as well as continuous hemodynamic and intramyocardial temperature monitoring. The defibrillation energy requirements were evaluated at 60-minute intervals with an epicardial patch system, and transcardiac impedance was measured before and after the multiple inductions and terminations of ventricular fibrillation. In group $1(n=10)$ defibrillation energy requirements were evaluated immediately after initiation of cardiopulmonary bypass at $37^{\circ} \mathrm{C}\left(\mathrm{T}_{\mathbf{0}}\right)$, after gradual cooling to $28^{\circ} \mathrm{C}\left(\mathrm{T}_{1}\right)$, and after rewarming to $37^{\circ} \mathrm{C}\left(\mathrm{T}_{2}\right)$. Group $2(n=16)$ comprised time controls that were identically instrumented and studied, but maintained at $37^{\circ} \mathrm{C}$ throughout. Percent successful defibrillation was plotted against delivered energy, and the raw data fit by logistic regression. The energy at which $50 \%$ of shocks were successful $\left(E_{50}\right)$ was $3.23 \pm 0.89$ joules at $T_{0}, 5.12 \pm 1.85$ joules at $T_{1}$, and $4.42 \pm 1.22$ joules at $T_{2}$ in group 1 ; this was not significantly different from the corresponding group $2 \mathrm{E}_{50}$ values, which were $3.11 \pm 1.39$ joules, $4.95 \pm 2.47$ joules, and $5.59 \pm 3.18$ joules, respectively. Both groups demonstrated a significant increase in $\mathbf{E}_{\mathbf{5 0}}$ during the first hour of cardiopulmonary bypass (mean increase from $T_{0}$ to $T_{1}$ was 1.89 joules in group 1 and 1.84 joules in group $2, p<$ 0.05). Transmyocardial impedance fell progressively during the group 2 experiments from 73.6 $\pm 12.9 \Omega$ at the beginning of the $T_{0}$ shock series to $61.4 \pm 8.9 \Omega$ at the end of the $\mathbf{T}_{2}$ shock series. A similar reduction in transmyocardial impedance was observed during the course of all the group 1 experiments; however, at the beginning of the $T_{1}$ shock series impedance was significantly elevated to $77.4 \pm 12.3 \Omega(p<$ 0.05 compared with group 2 and with end $T_{0}$ in group 1). There was no relationship between defibrillation energy requirements and transcardiac impedance; there was

David Martin, MBBS, MRCP, Jose Garcia, MD, ${ }^{\text {b, c }}$ C. Robert Valeri, MD, ${ }^{d}$ and Shukri F. Khuri, MD, ${ }^{\mathrm{b}, \mathrm{c}}$ with the technical assistance of Chee Lim, MS, and Mheir Doursounian, BS, Boston, Mass.
From the Department of Cardiology ${ }^{\mathrm{a}}$ and Surgical Service, ${ }^{\mathrm{b}}$ West Roxbury Veterans Administration Medical Center; Departments of Medicine a and Surgery, ${ }^{\mathrm{c}}$ Brigham and Women's Hospital and Harvard Medical School; and The Naval Blood Research Laboratory of Boston University School of Medicine, ${ }^{\mathrm{d}}$ Boston.

Presented in part at the Thirteenth Annual Scientific Session of the North American Society of Pacing and Electrophysiology, Chicago, Ill., May 14-16, 1992, and the Fourteenth Congress of the European Society of Cardiology, Barcelona, Spain, August 30-Sept. 3, 1992.

Supported by the United States Navy (Office of Naval Research Contracts N00014-79-C-0168 and N00014-88-C-0118, with the funds provided by the Naval Medical Research Command). Also supported by American Heart Association (Massachu- setts Affiliate) Physician Investigator Award to Dr. Garcia and by the Richard Warren Surgical Research and Educational Fund, Westwood, Mass.

The opinions or assertions contained herein are those of the authors and are not to be construed as official or reflecting the views of the Navy Department or Naval Service at large.

Received for publication June 14, 1994.

Accepted for publication Nov. 7, 1994.

Address for reprints: David Martin, MD, Department of Cardiology, Lahey Clinic Medical Center, 41 Mall Rd., Burlington, MA 01805.

J Thorac Cardiovasc Surg 1995;109:981-8

12/1/61885 
also no correlation between either of these parameters and intramyocardial extracellular pH or left ventricular end-diastolic pressure. We conclude that defibrillation energy requirements significantly and persistently increase during the first hour of cardiopulmonary bypass and the effect is temperature independent. Systemic hypothermia significantly and reversibly elevates transmyocardial impedance but multiple shocks reduce this effect at $28^{\circ} \mathrm{C}$ as they do at $37^{\circ} \mathrm{C}$. (J THORAC CARDIOvasC SURG 1995;109:981-8)

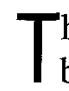
he placement of implantable cardioverter-defibrillators (ICDs) requires determination of defibrillation energy requirements (or defibrillation "threshold"; DFT) so that an adequate safety margin for device efficacy can be demonstrated. ${ }^{1,2}$ At least $10 \%$ of ICD implants are done concomitantly with cardiac operations that require cardiopulmonary bypass (CPB) and anoxic arrest; DFT testing is routinely done after such an operation is substantially complete and CPB has been partially or completely discontinued for only a few minutes. ${ }^{3}$

Anecdotal reports suggest that ICD implantation during operations in which CPB is used may be complicated by high DFT measurements; whether this is an immediate consequence of global ischemia or related to the mechanical effects of the pump is unknown. No rigorous assessment of the effect, if any, of normothermic and hypothermic CPB on the energy requirements for defibrillation has been done.

In a study designed to reflect clinical practice, we used a canine model of CPB to evaluate the influence of hypothermic and normothermic CPB on defibrillation energy requirements and transmyocardial impedance to defibrillatory shocks. We used a validated scientific method in which multiple inductions of ventricular fibrillation are required to generate dose-response curves of defibrillation efficacy. The effects of CPB on transmyocardial impedance were evaluated because of a reported relationship between impedance and DFT that remains controversial. ${ }^{4-6}$ In addition, CPB itself has been reported to have an effect on tissue impedance by virtue of its influence on water content. ${ }^{7}$ The experimental model used in this study is the first to permit accurate and stable control of myocardial temperature in an intact canine preparation. It was also our objective to define the relationships between intramyocardial $\mathrm{pH}$ (a measurement of the adequacy of tissue perfusion), transmyocardial impedance, and defibrillation energy requirements.

\section{Methods}

Animal preparation. All experimentation conformed with the requirements of the American Physiologic Society and the Animal Care Subcommittee of the Institutional Review Board of the West Roxbury Veterans Administration Medical Center. Adult male mongrel dogs weighing 30 to 35 pounds were anesthetized with sodium thiamylal $(20 \mathrm{mg} / \mathrm{kg}$ intravenously), paralyzed with succinylcholine $(20 \mathrm{mg}$ intravenously at the induction of anesthesia only), and maintained on a ventilator throughout the experiment. Further anesthesia was established with halothane as needed. Arterial and venous access and pressure monitoring were done with use of the carotid and jugular vessels. The heart was exposed via a left thoracotomy and suspended in a pericardial cradle. A high-fidelity micromanometer (Konigsberg Instruments, Pasadena, Calif.) was placed in the left ventricular cavity for measurement of developed and end-diastolic pressure, as well as the first time derivative of left ventricular pressure. Extracellular myocardial $\mathrm{pH}$ and myocardial temperature were continuously monitored in the anterior wall of the left ventricle with the use of previously described techniques. ${ }^{8-10}$

Defibrillating patches with a surface area of $14 \mathrm{~cm}^{2}$ (Cardiac Pacemakers, Inc., St. Paul, Minn.) were sutured to the epicardium over the lateral aspects of both right and left ventricles; these "small" clinical patches were chosen for their proportionally equal coverage of the epicardial surface of the canine heart compared with the coverage offered by the conventionally used "large" clinical patches for human implants. A closely spaced bipole was established with screw-in epicardial electrodes (Cardiac Pacemakers, Inc.) on the lateral wall of the left ventricle. These epicardial electrodes were used to deliver alternating current for the induction of ventricular fibrillation. Hemodynamic data (arterial and left ventricular pressure and the first time derivative of left ventricular pressure) were recorded continuously on a multichannel physiologic recorder, as were temperature and $\mathrm{pH}$ values. The defibrillating leads were connected to an external defibrillator (ECD-2, Cardiac Pacemakers, Inc.) that used a single-phase truncated exponential waveform of $60 \%$ tilt and variable pulse width, thus ensuring that selected and delivered energies were almost identical and unaffected by changes in transmyocardial impedance. This clinical device has reproducible energy delivery over the whole of its energy range of 0.1 to 40 joules; after a single battery charge the ECD-2 external defibrillator is capable of delivering more than 200 40-joule shocks (Cardiac Pacemakers, Inc., personal communication, 1992). 
Table I. Effects of duration of $C P B$

\begin{tabular}{|c|c|c|c|c|c|c|}
\hline & \multicolumn{3}{|c|}{ Hypothermic } & \multicolumn{3}{|c|}{ Normothermic } \\
\hline & $T_{0}\left(37^{\circ} \mathrm{C}\right)$ & $T_{1}\left(28^{\circ} \mathrm{C}\right)$ & $T_{2}\left(37^{\circ} \mathrm{C}\right)$ & $T_{0}\left(37^{\circ} \mathrm{C}\right)$ & $T_{1}\left(37^{\circ} \mathrm{C}\right)$ & $T_{2}\left(37^{\circ} \mathrm{C}\right)$ \\
\hline $\mathrm{E}_{50}$ (joules) & $3.23 \pm 0.89$ & $5.12 \pm 1.85^{*}$ & $4.42 \pm 1.22^{*}$ & $3.11 \pm 1.39$ & $4.95 \pm 2.47^{*}$ & $5.59 \pm 3.18^{*}$ \\
\hline HR (beats/min) & $131 \pm 13$ & $93 \pm 20^{*}$ & $141 \pm 19$ & $138 \pm 18$ & $136 \pm 24$ & $140 \pm 24$ \\
\hline $\operatorname{Imp}_{1}(\Omega)$ & $74.2 \pm 4.1$ & $77.4 \pm 12.3^{*}$ & $62.7 \pm 6.5$ & $73.6 \pm 12.9$ & $71.7 \pm 10.9$ & $64.3 \pm 6.8$ \\
\hline $\operatorname{Imp}_{2}(\Omega)$ & $72.6 \pm 8.7$ & $75.7 \pm 8.3^{*}$ & $61.4 \pm 9.6$ & $73.9 \pm 12.4$ & $67.6 \pm 7.6$ & $61.4 \pm 8.9$ \\
\hline $\mathrm{pH}_{1}$ & $7.48 \pm 0.20$ & $7.27 \pm 0.15^{*}$ & $7.37 \pm 0.15$ & $7.48 \pm 0.13$ & $7.49 \pm 0.14$ & $7.42 \pm 0.12$ \\
\hline $\mathrm{pH}_{2}$ & $7.41 \pm 0.18$ & $7.25 \pm 0.17^{*}$ & $7.29 \pm 0.12$ & $7.49 \pm 0.14$ & $7.44 \pm 0.13$ & $7.40 \pm 0.11$ \\
\hline LVEDP (mm Hg) & $1.9 \pm 2.1$ & $11.8 \pm 9.4^{*}$ & $3.6 \pm 5.5$ & $2.5 \pm 1.7$ & $2.6 \pm 2.1$ & $4.4 \pm 4.2$ \\
\hline
\end{tabular}

Note that $\mathrm{pH}$ measurements at $28^{\circ} \mathrm{C}$ are corrected for temperature assuming $\Delta \mathrm{pH} /{ }^{\circ} \mathrm{C}=-0.015 .{ }^{33} \mathrm{HR}$ denotes heart rate in beats per minute; Imp denotes transmyocardial impedance before defibrillation dose-response curve generation; $I m p_{2}$ denotes impedance immediately after completion of multiple shocks for curve generation; $\mathrm{pH}_{1}$ and $\mathrm{pH}_{2}$ are defined in the manner of $\operatorname{Imp} \mathrm{p}_{1}$ and $\operatorname{Imp} \mathrm{p}_{2}$, respectively. $T_{0}, T_{1}$, and $T_{2}$ refer to measurements made during the first, second, and third hours, respectively, of CPB.

${ }^{*} p<0.05$ compared with $T_{0}$.

After instrumentation the animal was heparinized (400 units $/ \mathrm{kg}$ ) and placed on full CPB by passage of right atrial (34F) and femoral arterial (16F) cannulas. A Sarns membrane oxygenator (Sarns Inc./3M, Ann Arbor, Mich.) with a centrifugal pump primed with $500 \mathrm{ml}$ of Ringer's lactate solution formed the core of the CPB circuit and flow was maintained at 2 to $2.5 \mathrm{~L} / \mathrm{min}$. No cardioplegia was administered, and the heart was allowed to continue beating in the partially unloaded state. Values of arterial blood gases, hematocrit, and serum electrolytes including calcium and magnesium were periodically measured and corrected as necessary during the experiment. Arterial pH was maintained between 7.35 and 7.45 at all times.

Experimental procedure. The defibrillation energy requirements were estimated in this study by the generation of dose-response curves from which the energy for $50 \%$ successful defibrillation (the $\mathrm{E}_{50}$ ) was derived. ${ }^{11-13}$ For each animal three dose-response curves of defibrillation efficacy were defined at three consistent time intervals: $T_{0}$, immediately after establishment of $\mathrm{CPB}$ at $37^{\circ} \mathrm{C} ; \mathrm{T}_{1}, 1$ hour after the beginning of the $T_{0}$ dose-response curve; and $T_{2}, 2$ hours after the beginning of the $T_{0}$ doseresponse curve. In group 1 animals the $T_{1}$ measurements were made after gradual cooling during a 20-minute period to $28^{\circ} \mathrm{C}$, and the $T_{2}$ data were generated after gradual rewarming to $37^{\circ} \mathrm{C}$. The target temperature of $28^{\circ} \mathrm{C}$ for cooling in group 1 experiments was chosen because it was the lowest temperature consistent with stable heart rhythm and hemodynamics. Temperatures below $28^{\circ} \mathrm{C}$ are frequently associated with atrial and ventricular arrhythmias, which may be intractable..$^{14-16}$ Group 2 animals acted as time controls: all dose-response curves were generated at $37^{\circ} \mathrm{C}$.

After stabilization at $37^{\circ} \mathrm{C}$, the transcardiac impedance was measured by delivery of a 2-joule shock during sinus rhythm ${ }^{17}$; the impedance was measured by the external defibrillator $50 \mu \mathrm{sec}$ into the pulse. This measurement was repeated after multiple shocks necessary for generation of the defibrillation efficacy data, and such measurements were duplicated at each time point. Ventricular fibrillation was induced by delivery of 2 seconds of alternating current, and, after a 10-second delay, a shock was delivered to attempt defibrillation. The initial energy selected was 15 joules, with energies for subsequent episodes of ventricular fibrillation delivered in decrements through $10,8,5,4,3,2$, and 1 joule until failure to defibrillate occurred. If the first shock of 15 joules failed to defibrillate, then initial shock energies for subsequent episodes of ventricular fibrillation were increased progressively to $20,25,30,35$, and 40 joules. After the first failure to defibrillate, subsequent energies were randomly selected from that energy, as well as the two higher and two lower settings available on the defibrillator, and multiple shocks at these energy settings were delivered to develop the dose-response curve. For each episode of ventricular fibrillation only the response to the initial shock was included in data analysis. After successful defibrillation, hemodynamic parameters and $\mathrm{pH}$ were allowed to return to baseline before reinduction of ventricular fibrillation. There was a minimum 2-minute delay between defibrillation and reinduction of ventricular fibrillation.

Data analysis. For each experiment at each time interval a logistic curve was generated relating percent successful defibrillation to stored energy. With the use of nonlinear regression the best fit to the following function was derived: $y=e^{x} /\left(1+e^{x}\right)$. The energy at which $50 \%$ of shocks successfully terminated ventricular fibrillation (the $E_{50}$ ) was derived from these curves. ${ }^{18}$ Because the animals used in this study were all of closely similar weight, and because there is no strong correlation between total body or excised heart weight and $\mathrm{E}_{50}$, the defibrillation energy requirements were not normalized for weight. ${ }^{19}$ Repeated-measures analysis of variance was done to determine whether $E_{50}$, transmyocardial impedance, or intramyocardial $\mathrm{pH}$ changed with time or temperature. Pairwise differences were tested using paired $t$ tests when the overall $\mathrm{F}$ test rejected the null hypothesis (Fisher's least significant difference procedure). Equality of variance in the normothermic and hypothermic groups was evaluated by pooling the $\log$ transformed $\mathrm{E}_{50}$ data for each animal and comparing variances by an $F$ test. Linear regression was used to explore the relationship between $E_{50}$ and transmyocardial impedance. All results are expressed as mean plus or minus the standard deviation. A $p$ value $<0.05$ was considered significant for all analyses. 


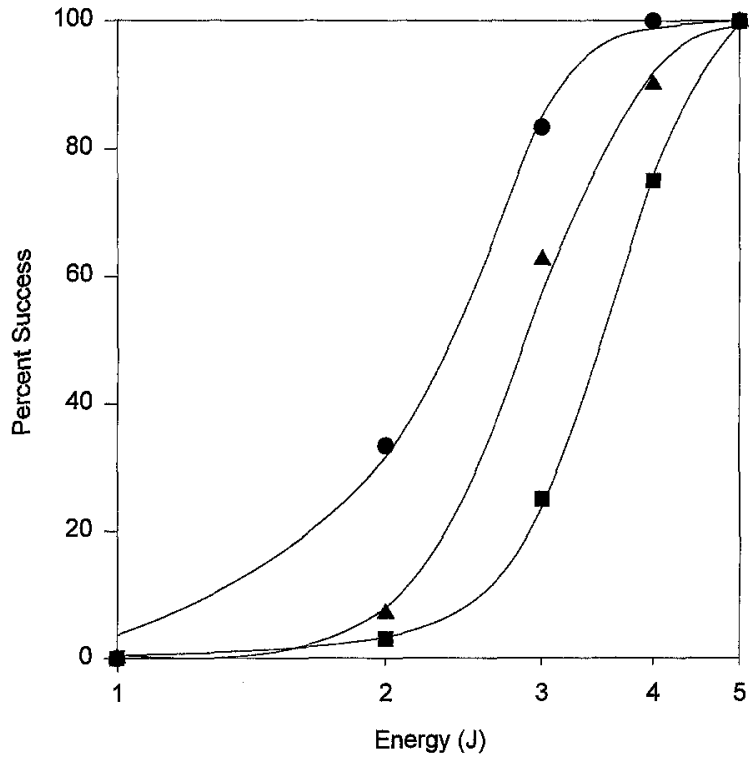

Fig. 1. Sample family of dose-response curves derived from single hypothermic (group 1) experiment. Circles denote measurements made immediately after establishment of CPB; triangles and squares denote repeated dose-response measurements made after 1 and 2 hours of $\mathrm{CPB}$, respectively. Note that abscissa scale is logarithmic.

\section{Results}

Of 35 dogs surgically prepared for this experimental protocol, nine became hemodynamically or metabolically unstable $(n=7)$ or were unable to be cannulated for CPB $(n=2)$. Results for the remaining 26 animals are presented; there were 10 group 1 (hypothermic) and 16 group 2 (normothermic) experiments reflecting increased wastage in the hypothermic cohort. Table I summarizes the effect of bypass duration on defibrillation energy requirements $\left(E_{50}\right)$, transmyocardial impedance, and intramyocardial $\mathrm{pH}$ in both groups.

Defibrillation energy requirements. The logistic model used in the derivation of the defibrillation dose-response curves satisfactorily fitted the data derived from each individual animal and there was no difference in variance of the data between the two groups. A sample family of dose-response curves from a single experiment is shown graphically in Fig. 1, and the pooled data are summarized in Fig. 2 . In both groups the $E_{50}$ immediately after establishment of CPB $\left(\mathrm{T}_{0}\right)$ was comparable (3.23 joules and 3.11 joules, $p=$ not significant). There was a significant increase in $E_{50}$ in both groups after the first hour of CPB $\left(T_{1}\right)$ to 5.12 joules in group 1 and 4.95 joules in group $2(p=0.0001)$. However, there

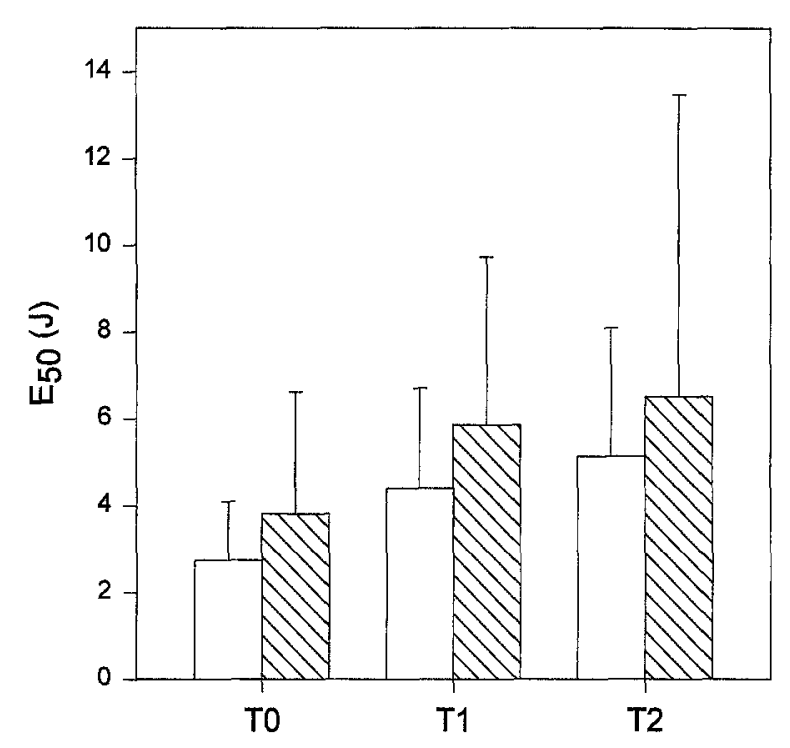

Fig. 2. Graph showing defibrillation energy requirements $\left(E_{50}\right)$ immediately after CPB is established $\left(T_{0}\right)$, after 1 hour $\left(\mathrm{T}_{1}\right)$, and after 2 hours $\left(\mathrm{T}_{2}\right)$. Hatched bars denote hypothermic (group 1) experiments; open bars denote normothermic (group 2) experiments.

remained no difference between the groups indicating no separate effect of hypothermia on the energy requirement for defibrillation. This elevation in $\mathrm{E}_{50}$ was sustained after the second hour of CPB $\left(\mathrm{T}_{1}\right)$ at 4.42 joules in group 1 and 5.59 joules in group 2 ( $p=$ not significant for both the between-group comparison and the within-group time effect).

Transmyocardial impedance. Resistance to the current of a 2-joule shock measured across the defibrillating patches during sinus rhythm ranged from $40 \Omega$ to $98 \Omega$ throughout the experiment in both groups. Impedance, computed as a percentage of baseline value, was significantly lower after the multiple shocks necessary for the generation of a dose-response curve compared with the precurve measurement in each group at each time interval with the exception of the $T_{0}$ data in group 2; this relative change in impedance from baseline is shown graphically in Fig. 3. Transmyocardial impedance increased significantly after cooling, rising from $74.2 \Omega$ at $37^{\circ} \mathrm{C}$ to $77.4 \Omega$ at $28^{\circ} \mathrm{C}$; after rewarming to $37^{\circ} \mathrm{C}$ impedance fell significantly to $62 \Omega$, which is not statistically different from the impedance of $64 \Omega$ in the group 2 animals at the same time interval. This elevation in impedance at $28^{\circ} \mathrm{C}$ is in marked contrast to the changes in transmyocardial impedance observed in the group 2 experiments over the same time course but at a constant $37^{\circ} \mathrm{C}$ : in 


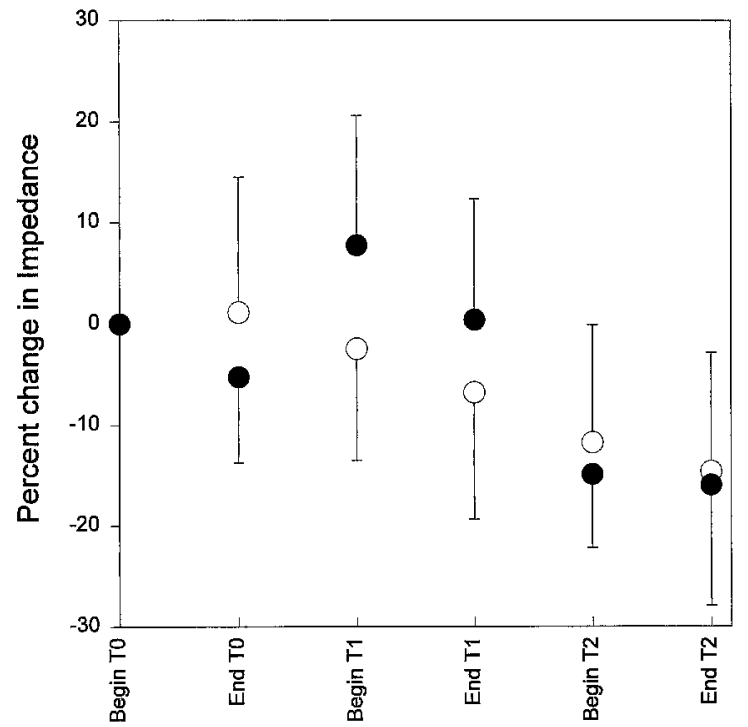

Fig. 3. Graph of pooled impedance data expressed as percentage of impedance at beginning of $T_{0}$ defibrillation dose-response curve generation plotted for beginning and end of each series of inductions of ventricular fibrillation. Closed circles denote hypothermic (group 1) experiments; open circles denote normothermic (group 2) experiments.

these latter experiments the impedance fell progressively during the period of cardiopulmonary bypass as illustrated in Fig. 2. Linear regression analysis disclosed no relationship between defibrillation energy requirements and the transmyocardial impedance $(r=0.06)$.

Intramyocardial pH. Extracellular intramyocardial acid-base balance remained stable throughout the experiments while the preparation was maintained at $37^{\circ} \mathrm{C}$. However, there was a significant acidosis at $28^{\circ} \mathrm{C}$, even after we corrected for the effect of temperature on the measurement, with a fall in mean $\mathrm{pH}$ from 7.48 at baseline to 7.27 after cooling (Fig. 4) ${ }^{20,21} \mathrm{Mean} \mathrm{pH}$ at $37^{\circ} \mathrm{C}$ ranged from 7.29 to 7.49 and no significant differences emerged when paired data from groups 1 and 2 were compared at similar time points provided the temperature was $37^{\circ} \mathrm{C}$. In addition, no changes were noted in paired $\mathrm{pH}$ values measured before and immediately after the multiple shocks necessary for the generation of the defibrillation efficacy dose-response curves.

Hemodynamic indices. Heart rate (mean 136 to 140 beats $/ \mathrm{min}$ ) remained stable throughout the experiment when the temperature was kept constant at $37^{\circ} \mathrm{C}$. However, heart rate fell significantly (from 131 to 93 beats/min) in group 1 animals after they

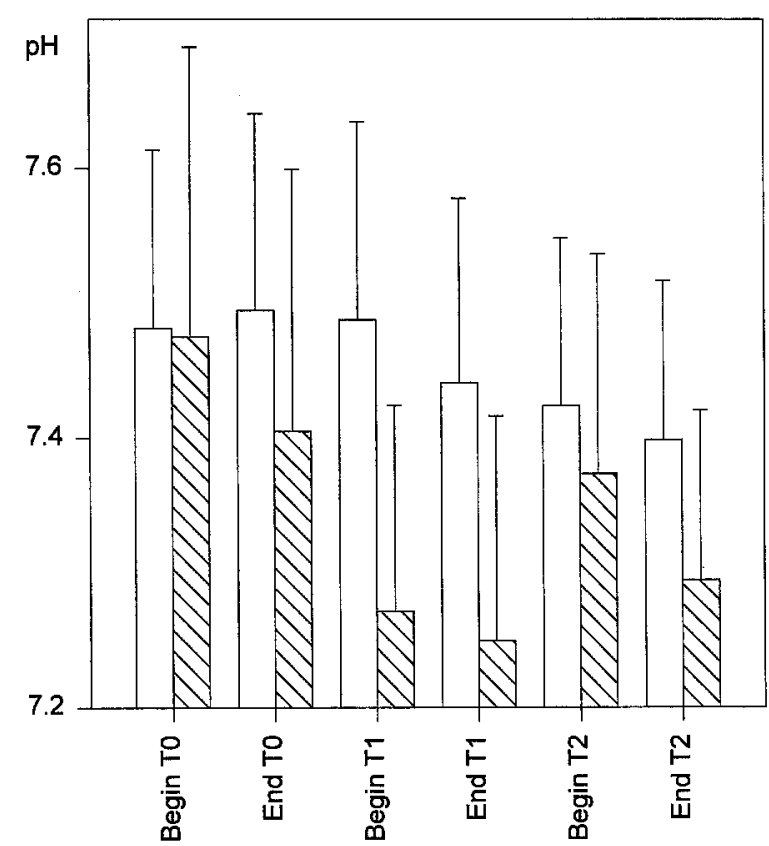

Fig. 4. Graph showing changes in extracellular intramyocardial $\mathrm{pH}$ during 2 hours of CPB. Symbols are as in Fig. 2.

were cooled to $28^{\circ} \mathrm{C}$ during the second hour of $\mathrm{CPB}$ (Fig. 5). Left ventricular end-diastolic pressure (LVEDP) remained low in all normothermic experiments with no significant change over the 2 hours of CPB. However, in group 1 the mean LVEDP rose significantly from $2.5 \mathrm{~mm} \mathrm{Hg}$ at $37^{\circ} \mathrm{C}$ to $11.8 \mathrm{~mm}$ $\mathrm{Hg}$ at $28^{\circ} \mathrm{C}$; after rewarming the mean LVEDP in these preparations returned to $3.6 \mathrm{~mm} \mathrm{Hg}$ as shown in Fig. 6. Despite the increase in both impedance and LVEDP at $28^{\circ} \mathrm{C}$, there was no correlation between these parameters $(r=0.12)$. In addition, there was no relationship between intramyocardial $\mathrm{pH}$ and LVEDP $(r=0.07)$.

\section{Discussion}

This is the first study to describe the effects of noncardioplegic CPB on defibrillation energy requirements as measured by the dose-response method. We have shown that the $\mathrm{E}_{50}$ increases significantly during the first hour of $\mathrm{CPB}$ and that hypothermia neither ameliorates nor exacerbates this effect. Our results differ from those of a study by Klein and co-workers ${ }^{22}$ in which the investigators reported no effect of CPB on defibrillation energy requirements. Their study included 10 patients undergoing cardiac surgery who underwent DFT measurement with a combined transvenous/epicardial 


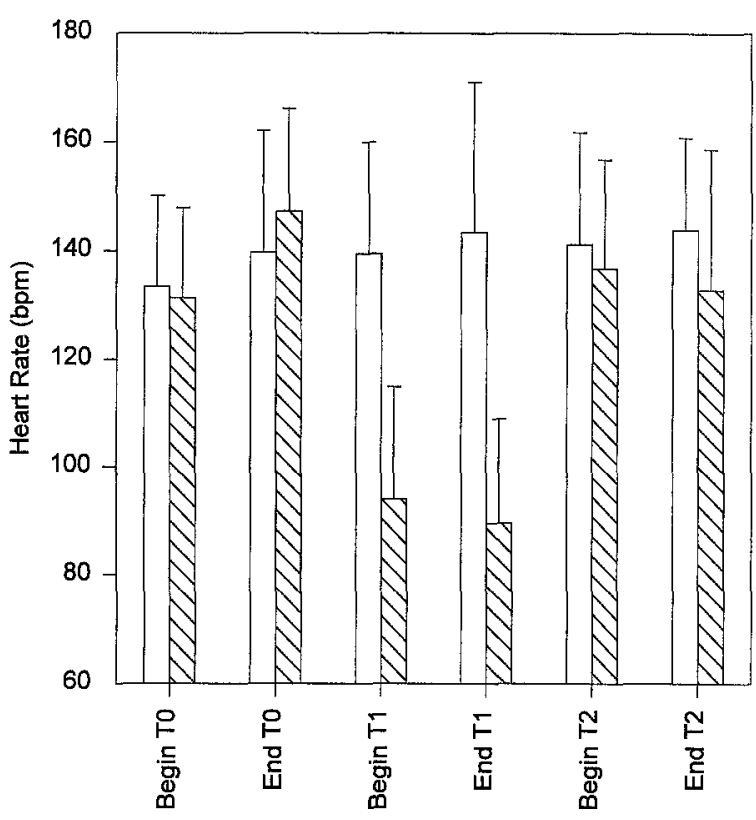

Fig. 5. Graph showing changes in heart rate during 2 hours of CPB. Symbols are as in Fig. 2.

system immediately after cannulation and $10 \mathrm{~min}$ utes after the establishment of full-flow bypass. In Klein's study DFT was measured with a method the reliability of which is now questioned by the same investigators. ${ }^{18}$ In contrast, our experimental protocol was designed to parallel clinical practice by allowing a longer duration of bypass and serial defibrillation threshold testing with use of a valid method.

The progressive reduction in transmyocardial impedance observed in our study during 2 hours of normothermic CPB confirms earlier observations on the effect of multiple shocks in which transthoracic defibrillation was used. ${ }^{23-25}$ After the generation of the defibrillation dose-response curve at $28^{\circ} \mathrm{C}$ the impedance in our study remained elevated albeit to a lesser degree, demonstrating that this multiple shock effect also occurs under hypothermic conditions.

The statistically significant increase in transmyocardial impedance both before and after multiple shocks at $28^{\circ} \mathrm{C}$ is an important finding that may have clinical relevance. The mean impedance increase at $28^{\circ} \mathrm{C}$ in our study was only $4 \%$, but $50 \%$ of the animals demonstrated an increase of more than $20 \%$. Elevations in impedance proportionally reduce energy delivery to myocardium when fixed pulse width defibrillators are used: therefore this

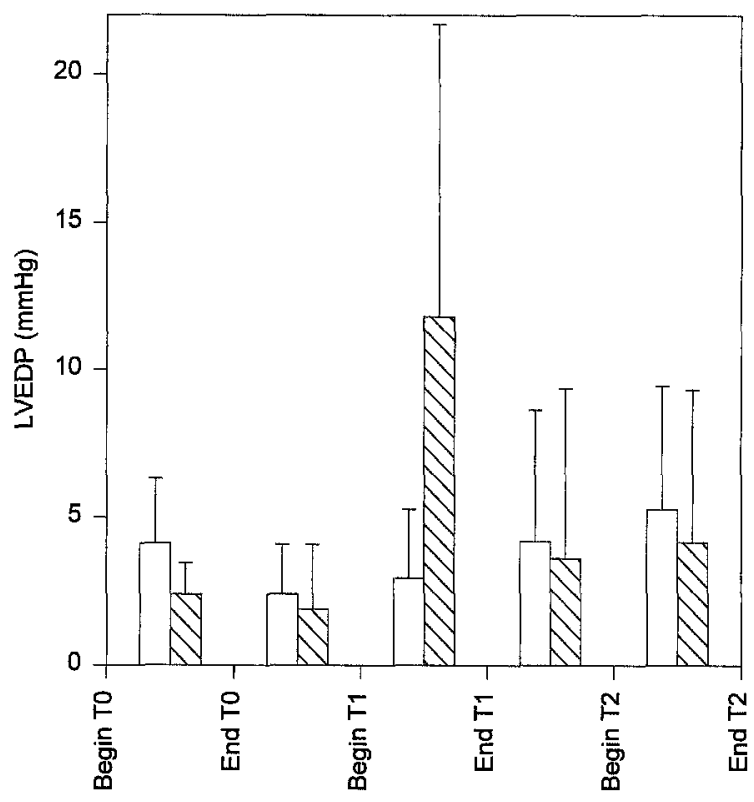

Fig. 6. Graph showing changes in LVEDP during 2 hours of CPB. Symbols are as in Fig. 2.

phenomenon may be at least partly responsible for impaired resuscitation in hypothermia and in other patients after prolonged ventricular fibrillation. ${ }^{26}$

The relative degree of intramyocardial acidosis (manifested by a significant reduction in temperature-corrected $\mathrm{pH}$ ) observed at $28^{\circ} \mathrm{C}$ may reflect ischemia, as is usually imputed from such values recorded clinically. ${ }^{10,27,28}$ However, it may be that the low $\mathrm{pH}$ reflected reduced washout rather than increased production of $\mathrm{H}^{+}$ions and that therefore there was no true intracellular acidosis. It is noteworthy that no animals in our study developed spontaneous ventricular fibrillation during cooling and that this degree of "acidosis" manifestly had no effect on defibrillation energy requirements. Our findings with regard to intramyocardial $\mathrm{pH}$ contrast with those of earlier clinical studies of acid-base status during hypothermic $\mathrm{CPB},{ }^{29,30}$ particularly with the work of Swain, White, and Peters. ${ }^{31}$ They reported that cardiac electrical stability (as evidenced by the ventricular fibrillation threshold) was improved by maintenance of alkaline $\mathrm{pH}$ (7.58) during hypothermia, thereby reproducing the metabolic adjustments made by ectothermic species. Our findings also differ from those of Echt, Cato, and Coxe,${ }^{11}$ who found that the elevating effect of lidocaine on defibrillation threshold was $\mathrm{pH}$-dependent and could be enhanced and reversed by acidosis and 
alkalosis, respectively. This variance in our data from those of previously published reports may be explained by the fact that we directly measured extracellular myocardial $\mathrm{pH}$ in contrast to most work, which has relied solely on arterial blood gas data, an insensitive index of myocardial acidosis. ${ }^{31}$

The elevation in LVEDP observed at $28^{\circ} \mathrm{C}$ reflects reduced myocardial compliance, possibly because of the edema associated with hypothermia; because of previous work from our laboratory elucidating the time course of ischemic damage under hypothermic conditions we do not believe the elevation in LVEDP is caused by ischemia. ${ }^{28}$ Although acute increases in ventricular volume and pressure have been shown in other models to be arrhythmogenic, ${ }^{32}$ it is noteworthy that in our study these significant elevations in LVEDP were not associated with increased spontaneous arrhythmia or increased energy requirements for defibrillation.

This study is limited by the inability to achieve "true" normothermia during CPB because of the open-chest nature of the model. Initial myocardial temperatures after the establishment of CPB were typically $35^{\circ} \mathrm{C}$ and all preparations were warmed to $37^{\circ} \mathrm{C}$ before initiation of ventricular fibrillation; however, the normal canine core temperature is $39^{\circ} \mathrm{C}$ and we were unable to achieve this for the normothermic testing protocol because of heat loss through the wound despite use of a radiant heat source above the operating field. Other potential limitations of this study relate to the true electrophysiologic comparability of groups 1 and 2 during the $\mathrm{T}_{1}$ testing period (at $28^{\circ} \mathrm{C}$ in group 1 and $37^{\circ} \mathrm{C}$ in group 2). The temperature difference between preparations in the two groups was responsible for the difference in heart rates and the significant bradycardia in the hypothermic group may account for the elevation in transmyocardial impedance. Because the ionic mechanism underlying the dynamics of myocardial electrical impedance is unknown, it remains unclear whether heart rate or temperature (alone or in combination) is responsible for this observation. Atrial pacing in the group 1 preparations during the $T_{1}$ testing (done to maintain constancy of heart rate) might have clarified this question, but would have deleteriously affected myocardial metabolism and the hemodynamic stability of the experimental preparation.

In conclusion, our data suggest that $\mathrm{CPB}$ has electrophysiologic effects that may have clinical importance. The significant elevation in defibrillation energy requirements observed in this study during both normothermic and hypothermic CPB is not related to changes in hemodynamic or acid-base status. Marked elevations in defibrillation threshold that may be observed clinically after CPB may therefore be the consequences of this procedure. Our study was done with normal canine hearts; pathologically enlarged, infarcted, or hypertrophic human hearts (the usual substrate in which ICD implantation is done) would be expected to exhibit more dramatic elevations in DFT after CPB. Further work is needed to define the duration of this effect after termination of bypass.

\section{REFERENCES}

1. Babbs CF, Whistler SJ, Yim GK. Temporal stability and precision of ventricular defibrillation threshold data. Am J Physiol 1978;235:H553-8.

2. Rattes MF, Jones DL, Sharma AD, Klein GJ. Defibrillation threshold: a simple and quantitative estimate of the ability to defibrillate. PACE Pacing Clin Electrophysiol 1987;10:70-7.

3. Troup PJ. Implantable cardioverters and defibrillators. Curr Probl Cardiol 1989;14:675-843.

4. Kerber RE, Jensen SR, Gascho JA, Grayzel J, Hoyt R, Kennedy J. Determinants of defibrillation: prospective analysis of 183 patients. Am J Cardiol 1983; 52:739-45.

5. Dalzell GW, Adgey AA. Determinants of successful transthoracic defibrillation and outcome in ventricular fibrillation. Br Heart J 1991;65:311-6.

6. Kerber RE, Kouba C, Martins J, et al. Advance prediction of transthoracic impedance in human defibrillation and cardioversion: importance of impedance in determining the success of low-energy shocks. Circulation 1984;70:303-8.

7. Garrido H, Sueiro J, Rivas J, Vilches J, Romero JM, Garrido F. Bioelectrical tissue resistance during various methods of myocardial preservation. Ann Thorac Surg 1983;36:143-51.

8. Khuri SF, Marston WA. On-line metabolic monitoring of the heart during cardiac surgery. Surg Clin North Am 1985;65:439-53.

9. Khuri SF, Marston W, Josa M, et al. First report of intramyocardial $\mathrm{pH}$ in man: I-methodology and initial results. Med Instrum 1984;18:167-71.

10. Khuri SF, Josa M, Marston W, et al. First report of intramyocardial $\mathrm{pH}$ in man: II-assessment of adequacy of myocardial preservation. J THORAC CARDIOVASC SURG 1983;86:667-78.

11. Echt DS, Cato EL, Coxe DR.pH-dependent effects of lidocaine on defibrillation energy requirements in dogs. Circulation 1989;80:1003-9.

12. Gliner BE, Murakawa Y, Thakor NV. The defibrillation success rate versus energy relationship: part I-curve fitting and the most efficient defibrillation 
energy. PACE Pacing Clin Electrophysiol 1990;13: 326-38.

13. Davy JM, Fain ES, Dorian P, Winkle RA. The relationship between successful defibrillation and delivered energy in open-chest dogs: reappraisal of the "defibrillation threshold" concept. Am Heart J 1987; 113:77-84.

14. Rankin AC, Rae AP. Cardiac arrhythmias during rewarming of patients with accidental hypothermia. Br Med J 1984;289:874-7.

15. Lloyd EL, Mitchell B. Factors affecting the onset of ventricular fibrillation in hypothermia. Lancet 1974;2: 1294-6.

16. Smith JM, Clancy EA, Valeri CR, Ruskin JN, Cohen RJ. Electrical alternans and cardiac electrical instability. Circulation 1988;77:110-21.

17. Leitch JW, Yee R, Klein GJ, Jones DL. Utility of low energy test shocks for estimation of cardiac and electrode impedance with implantable defibrillators. PACE Pacing Clin Electrophysiol 1990;13:410-6.

18. Jones DL, Irish WD, Klein GJ. Defibrillation efficacy: comparison of defibrillation threshold versus doseresponse curve determination. Circ Res 1991;69:45-51.

19. Echt DS, Black JN, Barbey JT, Coxe DR, Cato E. Evaluation of antiarrhythmic drugs on defibrillation energy requirements in dogs: sodium channel block and action potential prolongation. Circulation 1989; 79:1106-17.

20. Rahn H, Reeves RB. Hydrogen ion regulation during hypothermia. In: Prahosh O, ed. Applied physiology in respiratory care. Boston: Martinus Nijhoff, 1982:115.

21. Reeves RB. Temperature induced changes in blood acid-base status: $\mathrm{pH}$ and $\mathrm{pCO}_{2}$ in a binary buffer. $\mathrm{J}$ Appl Physiol 1986;40:752-61.

22. Klein GJ, Jones DL, Sharma AD, Kallok MJ, Guiraudon GM. Influence of cardiopulmonary bypass on internal cardiac defibrillation. Am J Cardiol 1986;57: 1194-5.

23. Geddes LA, Tacker WA, Cabler P, Chapman R, Rivera R, Kidder $\mathrm{H}$. The decrease in transthoracic impedance during successive ventricular defibrillation trials. Med Instrum 1975;9:179-80.

24. Dahl CF, Ewy GA, Ewy MD, Thomas ED. Transthoracic impedance to direct current discharge: effect of repeated countershocks. Med Instrum 1976;10:151-4.

25. Kerber RE, Grayzel J, Hoyt R, Marcus M, Kennedy J. Transthoracic resistance in human defibrillation: influence of body weight, chest size, serial shocks, paddle size and paddle contact pressure. Circulation 1981;63:676-82.

26. Mahmud R, Hsia PW, Jolly SR, Jordan JC. Changes in transmyocardial impedance during prolonged ventricular fibrillation: implications for current flow and delivered energy during DC countershock. Am Heart J 1990;120:334-9.

27. Khuri SF, Kloner RA, Hillis LD, et al. Intramural $\mathrm{PCO}_{2}$ : a reliable index of the severity of myocardial ischemic injury. Am J Physiol 1979;237:H253-9.

28. Lange R, Kloner RA, Zierler M, Carlson N, Seiler M, Khuri SF. Time course of ischemic alterations during normothermic and hypothermic arrest and its reflection by on-line monitoring of tissue $\mathrm{pH}$. J THORAC Cardiovasc Surg 1983;86:418-34.

29. Kroncke GM, Nichols RD, Mendenhall JT, Myerowitz PD, Starling JR. Ectothermic philosophy of acidbase balance to prevent fibrillation during hypothermia. Arch Surg 1986;121:303-4.

30. Matthews AJ, Stead AL, Abbott TR. Acid-base control during hypothermia. Acid-base control in children during hypothermia without temperature correction of $\mathrm{pH}$ and $\mathrm{PCO}_{2}$. Anaesthesia 1984;39:649-54.

31. Swain JA, White FN, Peters RM. The effect of $\mathrm{pH}$ on the hypothermic ventricular fibrillation threshold. J Thorac CaRdiovasc Surg 1984;87:445-51.

32. Hansen DE, Craig CS, Hondeghem LM. Stretchinduced arrhythmias in the isolated canine ventricle: evidence for the importance of mechanoelectrical feedback. Circulation 1990;81:1094-105.

33. Reeves RB. Temperature induced changes in blood acid-base status: $\mathrm{pH}$ and $\mathrm{pCO}_{2}$ in a binary buffer. $\mathbf{J}$ Appl Physiol 1986;40:752-61. 